EGU2020-9294

https://doi.org/10.5194/egusphere-egu2020-9294

EGU General Assembly 2020

(c) Author(s) 2021. This work is distributed under

the Creative Commons Attribution 4.0 License.

\title{
Deep geophysical investigation in urban area: Ferrara city example
}

\author{
Enzo Rizzo ${ }^{1,2}$, Luigi Capozzoli ${ }^{2}$, Gregory De Martino ${ }^{2}$, Sabatino Piscitelli ${ }^{2}$, Jessica Bellanova ${ }^{2}$, \\ Riccardo Caputo ${ }^{1}$, Vincenzo Lapenna ${ }^{2}$, Lorenzo Petronio ${ }^{3}$, Luca Baradello ${ }^{3}$, Alessandro Affatato ${ }^{3}$, \\ Gianfranco Morelli ${ }^{4}$, and Federico Fischanger ${ }^{4}$ \\ ${ }^{1}$ University of Ferrara, Dipartimento di Fisica e Scienze della Terra, Ferrara, Italy (enzo.rizzo@unife.it) \\ ${ }^{2}$ Consiglio Nazionale delle Ricerche, Istituto di Metodologie per le Analisi Ambientali (CNR-IMAA), Italy \\ ${ }^{3}$ OGS (Istituto Nazionale di Oceanografia e di Geofisica Sperimentale), Trieste, Italy \\ ${ }^{4}$ Geostudi Astier srl, Livorno, Italy
}

The role of applied geophysics for the new scenario of the increasing global urbanization is going to grow day by day. In this scenario a detailed knowledge of the geological subsoil and its iteration with urban infrastructures became a fundamental issue for urban planning. A novel sub-discipline, called Urban Geophysics (Lapenna, 2017), has recently been developing in the field of geophysics for analyzing limits and potentialities of well-known geophysical techniques in urban and industrialized areas. The application of some geophysical methods allows the recognition of geological structures from near surface down to more several hundred meters. The urban environment, characterized by a difficult logistic and a high level of noise, has a strong impact on the applicability of the geophysical prospecting methods and on the data quality.

This paper presents the results obtained by Deep Electrical Resistivity Tomography (DERT) and Pwave seismic reflection surveys performed in the city of Ferrara, which is interested in the management of geothermal resources and in the mitigation of seismic risk (CLARA-“Cloud Platform and smart underground imaging for natural risk assessment" Project funded by Italian MIUR). Along the eastern flank of the city walls, DERT and Reflection Seismic profiles were carried out in order to improve the geological information of the urban context.

DERT applications are not very common and there are only few published examples. It consists to inject direct current (square wave) into the ground, depending on the arrangement of the input points and the electrical resistivity of the subsoil, the shape of the electric field that is measured at the surface. The peculiarity of the DERT is the use of large electrode distances (>200 $\mathrm{m}$ ) and long profiles $(>3000 \mathrm{~m})$ in order to reach large investigation depths $(>300 \mathrm{~m})$.

Seismic reflection investigations offer a powerful nonDinvasive tool suitable for mapping the subsurface geological framework from the very nearपsurface to hundreds of metres below surface. Recently several seismic surveys was performed in urban environment by using frequencycontrolled vibroseis sources both in P-and SH-wave.

Along the eastern flank of the city walls, a DERT (5500m long) and a reflection seismic $(2500 \mathrm{~m}$ acquired by a MiniVib source in P-wave configuration) profiles were carried out in order to 
improve the geological information of the urban context. The joint interpretation of DERT and seismic data allowed to reconstruct the 'local' stratigraphic-depositional evolution until a depth of about $1 \mathrm{~km}$, and to highlight the occurrence of a sin-depositional Quaternary tectonic tilting associated to the growth of a fault-propagation fold. 